\title{
Pengaruh Penggunaan Media Sosial Twitter Terhadap Sikap Fanatisme Penggemar (Studi Pada Media Sosial Twitter @BTOBIndonesia Terhadap Sikap Fanatisme Penggemar)
}

\author{
Annisa Husnusyifa \\ Alumni Magister Ilmu Komunikasi Pascasarjana Unisba \\ e-mail : annisahusnusyifa@gmail.com
}

\begin{abstract}
Abstrak. Twitter merupakan jenis media sosial microblogging yang memfasilitasi pengguna untuk menulis dan memublikasikan aktivitas serta pendapatnya. Pada saat ini media sosial Twitter digunakan sebagai ekspresi kekaguman remaja terhadap idolanya, atau disebut sebagai perilaku fanatisme. Tujuan dari penelitian ini ialah untuk mengetahui bagaimana Pengaruh Penggunaan Media Sosial Twitter Terhadap Sikap Fanatisme Penggemar yang dilihat dari sisi tingkat penggunaan media sosial twitter, tingkat sikap fanatisme penggemar, dan adakah hubungan yang signifikan antara penggunaan media sosial twitter@BTOBIndonesia dengan sikap fanatisme penggemar BTOB di Bandung. Penelitian tesis ini pun didukung oleh teori Uses \& Gratification. Penelitian ini menggunakan metode kuantitatif dengan pendekatan kausal komparatif. Paradigma yang digunakan dalam penelitian ini yaitu Positivisme. Adapun teknik pengumpulan data yang digunakan dalam penelitian ini, yaitu kuesioner. Teknik sampling yang digunakan dalam penelitian ini adalah simple random sampling yaitu pengambilan anggota sampel dari populasi dilakukan secara acak tanpa memperhatikan strata yang ada dalam populasi itu. Hasil penelitian mendapatkan bahwa ada hubungan antara variabel Penggunaan Media Sosial Twitter (X) dengan Sikap Fanatisme Penggemar (Y) hal tersebut dapat ditunjukkan melalui uji t diketahui bahwa thitung dari konstanta adalah 2.731 lebih besar dari t-tabel 1.985. Berdasarkan analisis koefisien determinasi menunjukkan bahwa bahwa $36.1 \%$ sikap fanatisme penggemar (Y) dipengaruhi oleh variabel kebutuhan, frekuensi (X1) dan durasi (X2). Sedangkan sisanya yaitu $63.9 \%(100 \%-$ $36.1 \%$ ) dipengaruhi oleh variabel-variabel lainnya yang tidak diteliti dalam penelitian ini. Dengan demikian dapat disimpulkan dari hasil penelitian dan teori menunjukkan bahwa ternyata penggunaan media sosial twitter berpengaruh terhadap sikap fanatisme penggemar BTOB di Kota Bandung.
\end{abstract}

Kata Kunci : Pengaruh, Media Sosial, Twitter, Sikap Fanatisme, Penggemar

\begin{abstract}
Twitter is a type of microblogging social media that facilitates users to write and publish their activities and opinions. At this time social media Twitter is used as an expression of adolescent admiration of his idol, or referred to as the behavior of fanaticism. The purpose of this study is to find out how the Influence of Social Media Use Twitter Against Fanaticism Attitude Fans viewed from the side of the level of use of social media twitter, fanaticism fan level, and is there a significant relationship between the use of social media twitter @BTOBIndonesia with fanaticism attitude BTOB fans in Bandung. The research of this thesis is supported by Uses \& Gratification theory. This research uses quantitative method with comparative causal approach. The paradigm used in this research is Positivism. The data collection techniques used in this study, namely the questionnaire. The sampling technique used in this study is simple random sampling that is taking the sample members from the population is done randomly without considering the strata in the population. The result shows that there is a relationship between Social Media Use (X) variable and Fanisticism Attitude (Y) it can be shown by $t$ test it is known that $t$-count of constants is 2.731 bigger than t-table 1,985. Based on the analysis of coefficient of determination indicates that $36.1 \%$ fanatism attitude of $f a n(Y)$ is influenced by requirement, frequency (X1) and duration (X2). While the rest is $63.9 \%(100 \%-36.1 \%)$ influenced by other variables not examined in this study. Thus it can be concluded from the results of research and theory shows that the use of social media twitter has an influence on the attitude of fanaticism $B T O B$ fans in the city of Bandung.
\end{abstract}

Keywords: Influence, Social Media, Twitter, Fanatism Attitude, Fans 


\section{Pendahuluan}

Twitter merupakan jenis media sosial microblogging yang memfasilitasi pengguna untuk menulis dan memublikasikan aktivitas serta atau pendapatnya. Secara historis, kehadiran dan munculnya media sosial Twitter yang menyediakan ruang tertentu atau maksimal 140 karakter. Sama seperti media sosial lainnya, di Twitter pengguna bisa menjalin jaringan dengan pengguna lain, menyebarkan informasi, mempromosikan pendapat / pandangan pengguna lain, sampai membahas isu terhangat (trending topic) saat itu juga dan menjadi bagian dari isu tersebut dengan turut berkicau (tweet) menggunakan tagar (hastag) tertentu (Rulli, 2015: 43).

Melalui Twitter Penggemar Korean Wave secara terang-terangan dapat menyatakan rasa cinta kepada idola dengan menggunakan fungsi mention pada Twitter dan ditujukan langsung ke akun Twitter sang idola. Mereka dapat membahas banyak hal, dari mulai video klip yang rilis hingga foto-fotonya. Melalui Twitter mereka dapat dengan bebas mengungkapkan dan mencurahkan isi hati mereka kepada sesama penggemar dengan mempostingnya melalui Twitter (Nastiti, 2010). Dalam bidang bisnis sendiri, penggemar Korean Wave berlombalomba mencari keuntungan dari online shop dengan menjual album serta berbagai merchandise idola Korea dan mempromosikannya melalui Twitter.

Maraknya penggemar Korean Wave di Indonesia merebak hingga ke kota Bandung. Bandung terkenal dengan suasana kota yang menyenangkan dan masyarakatnya yang kreatif. Kota Bandung juga merupakan kota dengan penggemar Korean Wave terbanyak setelah Jakarta, terhitung ada banyak komunitas-komunitas dari penggemar Korean Wave, diantaranya BTOB Indonesia, iKONIC Bandung, YG Stan Bandung, SNSD Bandung, Super Junior Bandung dan sebagainya. Para komunitas Korean Wave tersebut sering menggunakan waktunya untuk
Fangirling $^{l}$ bahkan membuat kegiatan Gathering sebagai bentuk kecintaan dan sikap fanatisme mereka terhadap idolanya, salah satunya dari Komunitas (Fanbase) Boyband Korea BTOB.

Adapun pengaruh positif dan negatif dari kecintaan penggemar Korean Wave, salah satunya ialah ketika ramai kasus bunuh diri mengenai Idola Korea bernama Jonghyun anggota dari boygrup SHINee yang terjadi pada Desember tahun 2017. Para penggemar SHINee melakukan penggalangan dana untuk Palestina sebagai wujud untuk mengenang idolanya, Jonghyun yang telah tiada. Selain itu, kegiatan positif ini merupakan bentuk kesadaran bahwa meski penggemar bersedih akan kematiannya, tetapi mereka juga dapat bersimpati kepada yang lebih membutuhkan. Adapun pengaruh negatif dari kasus kematian ini ialah seperti yang dilansir dalam seleb.tempo.co, penggemar SHINee asal Indonesia yang belum diketahui identitasnya dikabarkan baru saja terlepas dari kritis dan tidak sadarkan diri menyusul kabar idolanya, Kim Jonghyun, pentolan grup SHINee yang tewas bunuh diri pada Senin, 18 Desember $2017^{2}$.

@BTOBIndonesia sebagai salah satu fanbase BTOB terbesar di Indonesia (berpusat di Bandung) yang berdiri sejak tahun 2012 yang tumbuh dan berkembang melalui media sosial Twitter dalam memperbaharui informasi mengenai BTOB. Kegiatan rutin yang dilakukan oleh@BTOBIndonesia ialah memberikan informasi terbaru mengenai BTOB dalam bentuk foto, teks dan video kepada 24.000 followers nya. Jumlah followers@BTOBIndonesia ini merupakan jumlah followers tertinggi di antara fanbase BTOB lainnya.

\footnotetext{
${ }^{1}$ Fangirling adalah sebutan untuk seseorang yang mengidolai idolanya dan mereka memiliki perasaan tersendiri yaitu Kesenangan yang mereka temukan dalam menidolai seorang idolanya itu.

${ }^{2}$ https://seleb.tempo.co/read/1043720/jonghy un-shinee-meninggal-penggemar-indonesiacoba-bunuh-diri
} 
Dari fenomena tersebut maka penulis tertarik untuk meneliti mengenai pengaruh penggunaan media sosial Twitter@BTOBIndonesia terhadap sikap fanatisme penggemar BTOB. Analisis dalam penelitian ini menggunakan teori Uses \& Gratification sebagai applied theory.

\section{PEMBAHASAN}

\section{a. Uji Validitas}

Uji validitas adalah suatu ukuran yang menunjukkan tingkat-tingkat kevalidan atau kesahihan sesuatu instrumen. Uji validitas digunakan untuk mengukur sah atau tidak validnya suatu kuesioner. Uji validitas dilakukan dengan menggunakan $r$ tabel. Nilai $r$ tabel untuk sampel 97 dengan tingkat signifikansi $5 \%$ menunjukkan $\mathrm{r}$ tabel sebesar 0.199. $\mathrm{R}$ table $=0.199(\mathrm{df}=\mathrm{n}-2$ $=97-2=95, \alpha=5 \%$ ). Jika $\mathrm{r}$ hitung lebih besar dari $r$ tabel dan nilai $r$ positif maka pertanyaan tersebut dikatakan valid. Berikut ini adalah hasil uji validitas.

Tabel 2a

Hasil Pengujian Validitas Instrumen

\begin{tabular}{|c|c|c|c|c|}
\hline Variabel & Item & r hitung & $r$ tabel & Keterangan \\
\hline \multirow{14}{*}{ Kebutuhan } & 1 & 0.556 & 0.199 & Valid \\
\hline & 2 & 0.539 & 0.199 & Valid \\
\hline & 3 & 0.562 & 0.199 & Valid \\
\hline & 4 & 0.485 & 0.199 & Valid \\
\hline & 5 & 0.488 & 0.199 & Valid \\
\hline & 6 & 0.475 & 0.199 & Valid \\
\hline & 7 & 0.424 & 0.199 & Valid \\
\hline & 8 & 0.541 & 0.199 & Valid \\
\hline & 9 & 0.387 & 0.199 & Valid \\
\hline & 10 & 0.513 & 0.199 & Valid \\
\hline & 11 & 0.513 & 0.199 & Valid \\
\hline & 12 & 0.471 & 0.199 & Valid \\
\hline & 13 & 0.517 & 0.199 & Valid \\
\hline & 14 & 0.495 & 0.199 & Valid \\
\hline \multirow{6}{*}{$\begin{array}{c}\text { Variabel X: } \\
\text { Penggunaan } \\
\text { Media } \\
\text { Sosial } \\
\text { Twitter }\end{array}$} & 15 & 0.574 & 0.199 & Valid \\
\hline & 16 & 0.479 & 0.199 & Valid \\
\hline & 17 & 0.262 & 0.199 & Valid \\
\hline & 18 & 0.567 & 0.199 & Valid \\
\hline & 19 & 0.434 & 0.199 & Valid \\
\hline & 20 & 0.232 & 0.199 & Valid \\
\hline \multirow{10}{*}{$\begin{array}{l}\text { Variabel Y: } \\
\text { Sikap } \\
\text { Fanatisme } \\
\text { Penggemar }\end{array}$} & 21 & 0.440 & 0.199 & Valid \\
\hline & 22 & 0.296 & 0.199 & Valid \\
\hline & 23 & 0.437 & 0.199 & Valid \\
\hline & 24 & 0.584 & 0.199 & Valid \\
\hline & 25 & 0.586 & 0.199 & Valid \\
\hline & 26 & 0.286 & 0.199 & Valid \\
\hline & 27 & 0.293 & 0.199 & Valid \\
\hline & 28 & 0.488 & 0.199 & Valid \\
\hline & 29 & 0.345 & 0.199 & Valid \\
\hline & 30 & 0.533 & 0.199 & Valid \\
\hline
\end{tabular}

Sumber : Data primer yang diolah, 2018

Berdasarkan dari uji validitas menunjukkan bahwa nilai $r$ hitung lebih besar dibanding nilai $r$ tabel. Dengan hasil ini maka kuesioner yang digunakan oleh variabel Kebutuhan (Need),
Penggunaan Media Sosial Twitter (X) dan Sikap Fanatisme Penggemar (Y) dinyatakan valid sebagai alat ukur variabel. 


\section{b. Uji Reliabilitas}

Uji reliabilitas digunakan untuk mengukur sejauh mana hasil suatu pengukuran dapat dipercaya. Dalam penelitian ini variabel dinyatakan reliabel dengan melihat nilai Cronbach's

Alpha pada setiap variabel. Apabila nilai Cronbach's Alpha masing-masing variabel > 0,70 (Sekaran, 2006:182). Maka butir-butir pertanyaan tersebut dinyatakan reliabel.

Tabel 2b

Hasil Pengujian Reliabilitas Instrumen

\begin{tabular}{|c|c|c|c|c|}
\hline Variabel & Sub Variabel & $\begin{array}{c}\text { Cronbach's Alpha } \\
\text { if Item Deleted }\end{array}$ & $\begin{array}{c}\text { Nilai } \\
\text { Alpha }\end{array}$ & Ket. \\
\hline \multirow{5}{*}{ Kebutuhan } & Kognitif & 0.798 & 0.820 & Reliabel \\
\hline & Afektif & 0.797 & 0.820 & Reliabel \\
\hline & $\begin{array}{l}\text { Integrasi } \\
\text { Personal }\end{array}$ & 0.805 & 0.820 & Reliabel \\
\hline & Integrasi Sosial & 0.804 & 0.820 & Reliabel \\
\hline & $\begin{array}{c}\text { Pelepasan } \\
\text { Ketegangan }\end{array}$ & 0.801 & 0.820 & Reliabel \\
\hline \multirow{2}{*}{$\begin{array}{c}\text { Variabel X: } \\
\text { Penggunaan } \\
\text { Media Sosial } \\
\text { Twitter }\end{array}$} & Frekuensi & 0.806 & 0.820 & Reliabel \\
\hline & Durasi & 0.803 & 0.820 & Reliabel \\
\hline \multirow{3}{*}{$\begin{array}{l}\text { Variabel Y: } \\
\text { Sikap } \\
\text { Fanatisme } \\
\text { Penggemar }\end{array}$} & $\begin{array}{c}\text { Komponen } \\
\text { Kognitif }\end{array}$ & 0.802 & 0.820 & Reliabel \\
\hline & $\begin{array}{l}\text { Komponen } \\
\text { Afektif }\end{array}$ & 0.813 & 0.820 & Reliabel \\
\hline & $\begin{array}{c}\text { Komponen } \\
\text { Konatif }\end{array}$ & 0.805 & 0.820 & Reliabel \\
\hline
\end{tabular}

Sumber : Data primer yang diolah, 2018

Dari data diatas dapat diketahui bahwa masing-masing variabel adalah reliabel dan layak digunkan dalam

\section{c. Uji Asumsi Klasik}

\section{c.1. Uji Normalitas}

Uji normalitas dilakukan untuk mengetahui apakah data sampel dalam penelitian ini telah terdistribusi secara normal. Model yang tinggi adalah yang memiliki ditribusi data yang normal atau mendekati normal (Ghozali, 2001). Hasil uji normalitas data dengan kuisioner karena karena mempunyai nilai alpha lebih besar dari 0,70 .

menggunakan analisis grafik yaitu grafik normal plot menunjukkan titik - titik menyebar disekitar garis diagonal serta penyebarannya mengikuti arah garis diagonal, hal ini berarti data berkompetensi normal. Analisis grafik dapat dilihat pada gambar dibawah ini: 
Gambar 2c1

Uji Normalitas

Normal P-P Plot of Regression Standardized Residual

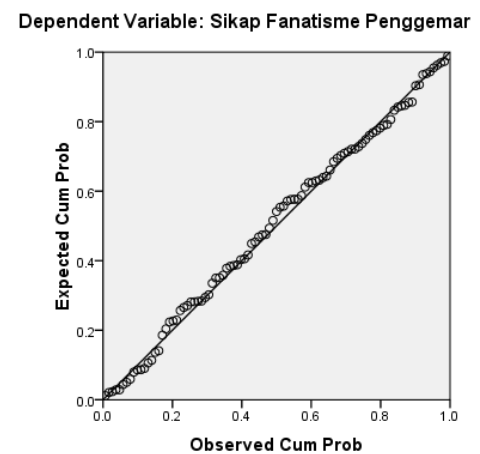

Gambar tersebut menunjukkan bahwa titik-titik residual model regresi sudah berkompetensi normal karena titik-titik tersebut yang menyebar di sekitar garis diagonal, serta penyebarannya mengikuti arah garis diagonal. Dengan demikian dari grafik tersebut menunjukkan bahwa model regresi layak dipakai karena memenuhi asumsi normalitas.

Uji normalitas dalam penelitian ini juga menggunakan uji kolmogorof Smirnov Test antara lain sebagai berikut:

Sumber: Hasil pengolahan data melalui SPSS, 2018

Tabel 2c1

Uji kolmogorof Smirnov test

\begin{tabular}{|l|l|r|}
\hline \multicolumn{2}{|c|}{ One-Sample Kolmogorov-Smirnov Test } \\
\hline \multicolumn{2}{|c|}{} & Unstandardized Residual \\
\hline $\mathrm{N}$ & Mean & .0000000 \\
\hline \multirow{2}{*}{ Normal Parameters ${ }^{\mathrm{a}}$} & Std. Deviation & 3.58521018 \\
\hline \multirow{2}{*}{$\begin{array}{l}\text { Most Extreme } \\
\text { Differences }\end{array}$} & Absolute & .049 \\
\cline { 2 - 3 } & Positive & .037 \\
\cline { 2 - 3 } & Negative & -.049 \\
\hline Kolmogorov-Smirnov Z & .486 \\
\hline Asymp. Sig. (2-tailed) & .972 \\
\hline a. Test distribution is Normal. \\
\hline \multicolumn{2}{|c|}{ Sumber: Hasil pengolahan data melalui SPSS, 2018 } \\
\hline
\end{tabular}

Berdasarkan tabel di atas dapat dilihat bahwa nilai signifikan sebesar 0.972 lebih besar 0,05. Hal ini dapat

\section{c.2 Uji Heteroskedastisitas}

Pengujian ini bertujuan untuk mendeteksi apakah kesalahan pengganggu dari model yang diamati tidak memiliki varians yang konstan dari satu observasi-keobservasi lainnya. Untuk mengetahui ada tidaknya gejala heteroskedastisitas dapat dilakukan dengan menggunakan grafik diartikan bahwa data berdistribusi normal.

heteroskesdastisitas untuk memprediksi nilai variabel dependen dengan variabel independen. Dari scaterplots terlihat titik-titik yang menyebar secara acak serta tersebar diatas maupun dibawah angka 0 pada sumbu Y. Di bawah ini adalah gambar dari hasil pengujian heteroskedastisitas. 
Gambar 2c2

Uji Heteroskedastisitas

Scatterplot

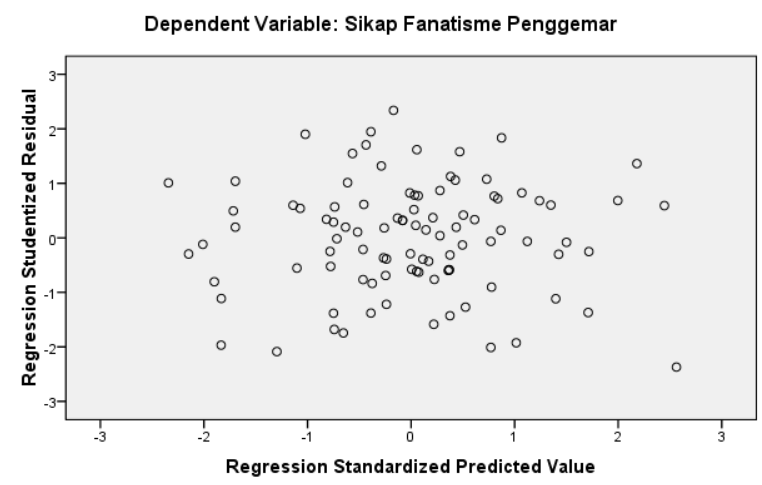

Sumber: Hasil pengolahan data melalui SPSS, 2018

Hasil pengujian

heteroskedastisitas menunjukkan tidak terdapat pola yang jelas dari titik-titik tersebut dan titik - titik menyebar diatas maupun dibawah angka nol pada sumbu Y. Hal ini menunjukkan bahwa model

\section{c.3 Uji Multikoleniaritas}

Uji multikolinearitas bertujuan untuk menguji apakah model regresi ditemukan adanya korelasi antar variabel bebas (independent). Model regresi yang tinggi seharusnya tidak terjadi korelasi antar variabel bebas. Untuk mendeteksi gejala Multikolinearitas dilakukan dengan cara melihat nilai (VIF) Variance Inflation regresi yang digunakan dalam penelitian ini tidak memiliki gejala adanya heteroskedastisitas, yang berarti bahwa tidak ada gangguan yang berarti dalam model regresi ini.

Factor (Ghozali, 2009). Pada perhitungan ini tidak ada satupun variabel independen yang memiliki VIF lebih dari 10 , maka data ini bebas dari Multikolinearitas. Sedangkan berdasarkan nilai tolerance tidak ada satupun variabel independen yang memiliki tolerance lebih dari 0,1 . Untuk hasil selengkapnya dapat dilihat dari tabel di bawah ini:

Tabel 2c3

Uji Multikoleniaritas

\begin{tabular}{|c|c|c|c|}
\hline \multicolumn{4}{|c|}{ Coefficients $^{\mathrm{a}}$} \\
\hline \multirow{2}{*}{\multicolumn{2}{|c|}{ Model }} & \multicolumn{2}{|c|}{ Collinearity Statistics } \\
\hline & & Tolerance & VIF \\
\hline \multirow[t]{4}{*}{1} & (Constant) & & \\
\hline & Kebutuhan & .831 & 1.203 \\
\hline & Frekuensi & .399 & 2.509 \\
\hline & Durasi & .407 & 2.457 \\
\hline \multicolumn{4}{|c|}{$\begin{array}{l}\text { a. Dependent Variable: Sikap Fanatisme } \\
\text { Penggemar }\end{array}$} \\
\hline
\end{tabular}

Nilai VIF untuk masing-masing variabel independen dalam persamaan memiliki nilai kurang dari 10 dan nilai tolerance lebih besar dari 0,10 maka semua variabel dalam model tidak terkena masalah multikolinearitas. Hal ini dapat disimpulkan bahwa semua variabel bebas tidak mepunyai korelasi yang sangat kuat. 


\section{d. Analisis Regresi Linier Berganda}

Adapun regresi linier berganda menggunakan SPSS versi 16.00 antara lain sebagai berikut:

Tabel 2d

Analisis Regresi Linier Berganda

\begin{tabular}{|c|c|c|c|c|c|c|}
\hline \multicolumn{7}{|c|}{ Coefficients $^{\mathrm{a}}$} \\
\hline & \multirow{2}{*}{ Model } & \multicolumn{2}{|c|}{$\begin{array}{l}\text { Unstandardized } \\
\text { Coefficients }\end{array}$} & \multirow{2}{*}{$\begin{array}{c}\text { Standardized } \\
\text { Coefficients } \\
\text { Beta }\end{array}$} & \multirow[t]{2}{*}{$\mathrm{t}$} & \multirow{2}{*}{ Sig. } \\
\hline & & B & Std. Error & & & \\
\hline \multirow{4}{*}{1} & (Constant) & 8.846 & 3.239 & & 2.731 & .008 \\
\hline & Kebutuhan & .440 & .068 & .583 & 6.517 & .000 \\
\hline & Frekuensi & -.114 & .255 & -.058 & -.448 & .655 \\
\hline & Durasi & .307 & .295 & .133 & 1.042 & .300 \\
\hline \multicolumn{5}{|c|}{ a. Dependent Variable: Sikap Fanatisme Penggemar } & & \\
\hline
\end{tabular}

Sumber: Hasil pengolahan data melalui SPSS, 2018

Sehingga dari persamaan rumus regresi linier berganda dapat diperoleh hasil sebagai berikut:

\section{$\mathrm{Y}=\mathbf{8 . 8 4 6}+\mathbf{0 . 4 4 0}+-\mathbf{- 0 . 1 1 4} \mathrm{X} 1+0.307 \mathrm{X} 2$}

Hasil persamaan regresi berganda tersebut diatas memberikan pengertian bahwa:

1. Nilai konstanta sebesar 8.846 menunjukkan bahwa variabel Kebutuhan (Need), Frekuensi dan Durasi jika tidak ada perubahan maka Sikap Fanatisme Penggemar cenderung positif.

2. Nilai koefisien Kebutuhan (Need) sebesar 0.440 bernilai positif. Hal ini dapat diartikan bahwa kebutuhan (Need) berpengaruh terhadap sikap fanatisme penggemar.

3. Nilai koefisien Frekuensi ( $\beta 1)$ sebesar -0.114 dengan nilai negatif. Hal ini berarti bahwa Frekuensi (X1) tidak berpengaruh terhadap sikap fanatisme penggemar.

4. Nilai koefisien Durasi ( $\beta 2)$ sebesar 0.307 dengan nilai positif. Hal ini berarti bahwa Durasi (X2) berpengaruh terhadap sikap fanatisme penggemar.

\section{e. Uji Signifikansi Parameter Individual (Uji Statistik t)}

Uji statistik $t$ pada dasarnya menunjukkan seberapa jauh pengaruh satu variabel independen secara parsial dalam menerangkan variasi variabel dependen. Dalam penelitian ini menggunakan signifikansi level 0,05 ( $\alpha$ $=5 \%$ ) untuk Kebutuhan, Frekuensi dan Durasi. Jika t-hitung $<\mathrm{t}$-tabel, maka variabel independen secara parsial tidak berpengaruh terhadap variabel dependen (hipotesis ditolak). Sedangkan jika thitung > t-tabel, maka variabel independen secara parsial berpengaruh terhadap variabel dependen (hipotesis diterima).

Kekuatan hubungan yang terjadi diantara masing-masing variabel independen terhadap variabel dependen adalah sebagai berikut:

Tabel 2e

Uji t

\begin{tabular}{|c|c|c|c|c|c|c|}
\hline \multicolumn{7}{|c|}{ Coefficients $^{\text {a }}$} \\
\hline & \multirow[t]{2}{*}{ Model } & \multicolumn{2}{|c|}{ Unstandardized Coefficients } & $\begin{array}{c}\text { Standardized } \\
\text { Coefficients }\end{array}$ & \multirow[t]{2}{*}{$\mathrm{t}$} & \multirow[t]{2}{*}{ Sig. } \\
\hline & & $\mathrm{B}$ & Std. Error & Beta & & \\
\hline \multirow{4}{*}{1} & (Constant) & 8.846 & 3.239 & & 2.731 & .008 \\
\hline & Kebutuhan & .440 & .068 & .583 & 6.517 & .000 \\
\hline & Frekuensi & -.114 & .255 & -.058 & -.448 & .655 \\
\hline & Durasi & .307 & .295 & .133 & 1.042 & .300 \\
\hline \multicolumn{7}{|c|}{ a. Dependent Variable: Sikap Fanatisme Penggemar } \\
\hline
\end{tabular}


1. Berdasarkan hipotesis pertama yang diajukan oleh peneliti menunjukkan bahwa variabel Kebutuhan (Need) berpengaruh terhadap sikap fanatisme penggemar. Dijelaskan pula dalam hasil analisis regresi bahwa variabel kebutuhan mempunyai nilai t-hitung 6.517 lebih besar dari t-tabel 1.985 dan diperoleh nilai signifikansi 0.000 lebih kecil dari taraf signifikansi 0.05. Oleh karena itu dapat disimpulkan bahwa hipotesis diterima.

2. Hipotesis kedua dijelaskan dalam variabel Frekuensi yang mempunyai nilai t-hitung - 0.448 lebih kecil dari t-tabel 1.985 dan diperoleh nilai signifikansi 0.655 lebih besar dari taraf signifikansi 0.05 . Oleh karena itu, dapat disimpulkan bahwa Frekuensi tidak berpengaruh terhadap sikap fanatisme penggemar, maka hipotesis ditolak.

3. Hipotesis ketiga dijelaskan dalam variabel Durasi yang mempunyai nilai t-hitung 1.042 lebih kecil dari t-tabel 1.985 dan diperoleh nilai signifikansi 0.300 lebih besar dari taraf signifikansi 0.05 . Oleh karena itu, dapat disimpulkan bahwa Durasi tidak berpengaruh terhadap sikap fanatisme penggemar, maka hipotesis ditolak.

\section{f. Uji Signifikansi Paramater Secara Simultan (Uji Statistik F)}

Uji $F$ dalam penelitian ini menggunakan uji ANOVA. Uji ini dapat digunakan untuk mengetahui pengaruh bersama-sama (simultan) variabel bebas (kebutuhan, frekuensi dan durasi) terhadap variabel terikat (sikap fanatisme penggemar). Dasar pengambilan keputusannya adalah sebagai berikut:

1. Menetapkan variable yang bermakna dengan membandingkan $\mathrm{F}$ hitung dan $\mathrm{F}$ tabel, apabila $\mathrm{F}$ hitung $>\mathrm{F}$ tabel, maka $\mathrm{H}_{0}$ ditolak dan $\mathrm{H}_{1}$ diterima. Sedangkan jika $\mathrm{F}_{\text {hitung }}$ $<\mathrm{F}$ tabel, $\mathrm{H}_{0}$ diterima dan $\mathrm{H}_{1}$ ditolak.

2. $F$ tabel dilihat pada tingkat keyakinan $5 \%(\alpha=0,05)$, dan derajat kebebasan $(\mathrm{dk})=\mathrm{n}-\mathrm{k}-1$.

a. Hasil perhitungan uji $F$ dapat dilihat pada tabel berikut ini:

\begin{tabular}{|c|c|c|c|c|c|c|}
\hline & \multicolumn{4}{|c|}{$\begin{array}{c}\text { Tabel 2f } \\
\text { Uii F }\end{array}$} & & \\
\hline & Model & $\begin{array}{l}\text { Sum of } \\
\text { Squares }\end{array}$ & $\mathrm{df}$ & Mean Square & $\mathrm{F}$ & Sig. \\
\hline \multirow{3}{*}{1} & Regression & 758.537 & 3 & 252.846 & 19.056 & $.000^{\mathrm{a}}$ \\
\hline & Residual & 1233.958 & 93 & 13.268 & & \\
\hline & Total & 1992.495 & 96 & & & \\
\hline
\end{tabular}

Sumber: Hasil pengolahan data melalui SPSS, 2018

Pengujian pengaruh variabel bebas secara bersama-sama terhadap variabel terikatnya dilakukan dengan menggunakan uji F. Hasil perhitungan statistik menunjukkan nilai $\mathrm{F}$ hitung $=$ 19.056 lebih dari $\mathrm{F}$ tabel $=3.09$ dan signifikansi sebesar $0.000<0.05$. Sikap fanatisme penggemar dipengaruhi secara bersama-sama dan signifikan oleh variabel kebutuhan, frekuensi, dan durasi.

\section{g. Analisis Koefisien Determinasi}

Koefisien determinasi ini digunakan untuk mengenai seberapa besar pengaruh variabel-variabel bebas memiliki pengaruh terhadap variabel terikatnya. Nilai koefisien determinasi untuk variabel bebas lebih dari 2 digunakan adjusted $\mathrm{R}$ square, sebagai berikut: 
Tabel 2g

Koefisien Determinasi

\begin{tabular}{|c|c|c|c|c|c|}
\hline \multicolumn{7}{|c|}{ Model Summary $^{\mathbf{b}}$} \\
\hline Model & $\mathrm{R}$ & R Square & $\begin{array}{c}\text { Adjusted R } \\
\text { Square }\end{array}$ & $\begin{array}{c}\text { Std. Error of the } \\
\text { Estimate }\end{array}$ & Durbin-Watson \\
\hline 1 & $.617^{\mathrm{a}}$ & .381 & .361 & 3.64258 & 2.086 \\
\hline \multicolumn{7}{l}{} \\
a. Predictors: (Constant), Durasi, Kebutuhan, Frekuensi \\
b. Dependent Variable: Sikap Fanatisme Penggemar \\
\hline
\end{tabular}

Sumber: Hasil pengolahan data melalui SPSS, 2018

Dari hasil perhitungan dengan menggunakan program SPSS dapat diketahui bahwa koefisien determinasi (adjusted $\mathrm{R}^{2}$ ) yang diperoleh sebesar 0.361. Hal ini berarti $36.1 \%$ sikap fanatisme penggemar (Y) dapat dipengaruhi oleh variabel kebutuhan, frekuensi (X1) dan durasi (X2). Sedangkan sisanya yaitu $63.9 \%(100 \%$ - $36.1 \%$ ) dipengaruhi oleh variabelvariabel lainnya yang tidak diteliti dalam penelitian ini.

\section{Pembahasan :}

Twitter adalah sebuah situs web yang dimiliki dan dioprasikan oleh Twitter Inc., yang menawarkan jejaring sosial berupa mikroblog sehingga memungkinkan penggunaanya untuk mengirim dan membaca pesan yang disebut kicauan (tweets). Kicauan adalah teks tulisan hingga 140 karakter yang ditampilkan pada halaman profil pengguna. Kicauan bisa dilihat secara luar, namun pengirim dapat membatasi pengirim pesan ke daftar teman-teman meraka saja.

Oleh karena itu penelitian ini bertujuan untuk mengetahui Pengaruh Penggunaan Media Sosial Twitter Terhadap Sikap Fanatisme Penggemar. Berdasarkan hasil karakteristik responden diketahui bahwa responden sebagian besar berjenis kelamin wanita adalah 96 orang, sedangkan yang berjenis kelamin laki-laki adalah 1 orang. Berdasarkan umur, responden lebih dominan berusia $\leq 20$ yaitu berjumlah 56 orang, sedangkan yang berusia 21 - 30 tahun berjumlah 31 orang, dan $\geq 31$ hanya 10 orang. Berdasarkan pendidikan, responden mayoritas berstatus Mahasiswa dengan jumlah 37 orang, sedangkan yang berstatus pelajar SMP berjumlah 26 orang, dan yang berstatus sebagai pelajar SMA berjumlah 34 orang. Berdasarkan lama menjadi penggemar, yaitu responden yang menjadi penggemar BTOB $\geq 5$ Tahun sebanyak 28 orang, sedangkan yang menjadi penggemar BTOB selama 3-5 Tahun sebanyak 20 orang, yang menjadi penggemar BTOB selama 1-3 Tahun sebanyak 37 orang, dan yang menjadi penggemar BTOB selama 3-6 bulan sebanyak 12 orang.

Berdasarkan dari uji validitas bahwa nilai $r$ tabel untuk sampel 97 dengan tingkat signifikansi $5 \%$ menunjukkan $\mathrm{r}$ tabel sebesar 0.199. $\mathrm{R}$ table $=0.199(\mathrm{df}=\mathrm{n}-2=97-2=95, \alpha=$ $5 \%$ ). Jika $r$ hitung lebih besar dari $r$ tabel dan nilai $r$ positif maka pertanyaan tersebut dikatakan valid. Berdasarkan dari uji validitas menunjukkan bahwa nilai $r$ hitung lebih besar dibanding nilai $r$ tabel. Dengan hasil ini maka kuesioner yang digunakan oleh variabel Kebutuhan (Need), Penggunaan Media Sosial Twitter (X) dan Sikap Fanatisme Penggemar (Y) dinyatakan valid sebagai alat ukur variabel.

Berdasarkan uji reliabilitas dalam penelitian ini variabel dinyatakan reliabel dengan melihat nilai Cronbach's Alpha pada setiap variabel. Apabila nilai Cronbach's Alpha masing-masing variabel > 0,70 (Sekaran, 2006:182). Maka butir-butir pertanyaan dalam penelitian ini dinyatakan reliabel. Dari data penelitian ini dapat diketahui bahwa masing-masing variabel adalah reliabel dan layak digunkan dalam kuisioner karena karena mempunyai nilai alpha lebih besar dari 0,70 , yaitu 0.820 . 
regresi $\begin{gathered}\text { Berdasarkan hasil analisis } \\ \text { berganda }\end{gathered}$ menunjukkan bahwa nilai konstanta adalah sebesar 8.846, hal ini dapat diartikan bahwa variabel Kebutuhan (Need), Frekuensi dan Durasi jika tidak ada perubahan maka Sikap Fanatisme Penggemar cenderung nerpengaruh positif. Nilai koefisien Kebutuhan (Need) sebesar 0.440 bernilai positif, hal ini dapat diartikan bahwa kebutuhan (Need) berpengaruh terhadap sikap fanatisme penggemar. Nilai koefisien Frekuensi ( $\beta 1$ ) sebesar -0.114 dengan nilai negatif, hal ini berarti bahwa Frekuensi (X1) tidak berpengaruh terhadap sikap fanatisme penggemar. Dan nilai koefisien Durasi ( $\beta 2)$ sebesar 0.307 dengan nilai positif, hal ini berarti bahwa Durasi (X2) berpengaruh terhadap sikap fanatisme penggemar.

Berdasarkan hasil uji t diketahui bahwa Berdasarkan hipotesis pertama yang diajukan oleh peneliti menunjukkan bahwa variabel Kebutuhan (Need) berpengaruh terhadap sikap fanatisme penggemar. Dijelaskan pula dalam hasil analisis regresi bahwa variabel kebutuhan mempunyai nilai thitung 6.517 lebih besar dari t-tabel 1.985 dan diperoleh nilai signifikansi 0.000 lebih kecil dari taraf signifikansi 0.05 . Oleh karena itu dapat disimpulkan bahwa hipotesis diterima.

Hipotesis kedua dari hasil uji t dijelaskan dalam variabel Frekuensi yang mempunyai nilai t-hitung -0.448 lebih kecil dari t-tabel 1.985 dan diperoleh nilai signifikansi 0.655 lebih besar dari taraf signifikansi 0.05 . Oleh karena itu, dapat disimpulkan bahwa Frekuensi tidak berpengaruh terhadap sikap fanatisme penggemar, maka hipotesis ditolak.

Hipotesis ketiga dari hasil uji $\mathrm{t}$ dijelaskan dalam variabel Durasi yang mempunyai nilai t-hitung 1.042 lebih kecil dari t-tabel 1.985 dan diperoleh nilai signifikansi 0.300 lebih besar dari taraf signifikansi 0.05 . Oleh karena itu, dapat disimpulkan bahwa Durasi tidak berpengaruh terhadap sikap fanatisme penggemar, maka hipotesis ditolak.
Berdasarkan hasil uji $\mathrm{F}$ penelitian ini menunjukkan nilai $\mathrm{F}$ hitung $=19.056$ lebih dari $\mathrm{F}$ tabel $=$ 3.09 dan signifikansi sebesar $0.000<$ 0.05 . Sikap fanatisme penggemar $(\mathrm{Y})$ dipengaruhi secara bersama-sama dan signifikan oleh variabel kebutuhan (need), frekuensi (X1), dan durasi (X2).

Berdasarkan analisis koefisien determinasi dengan menggunakan program SPSS menunjukkan bahwa koefisien determinasi (adjusted $\mathrm{R}^{2}$ ) yang diperoleh sebesar 0.361. Hal ini dapat diartikan bahwa $36.1 \%$ sikap fanatisme penggemar (Y) dapat dipengaruhi oleh variabel kebutuhan, frekuensi (X1) dan durasi (X2). Sedangkan sisanya yaitu $63.9 \%(100 \%$ - 36.1\%) dipengaruhi oleh variabel-variabel lainnya yang tidak diteliti dalam penelitian ini.

Hasil penelitian ini dikaitkan dengan teori yang digunakan dalam penelitian ini. Teori pertama adalah Psikologi Humanistik yang menyatakan bahwa dimensi manusia dalam berhubungan dengan lingkungannya secara manusiawi dengan menitikberatkan pada kebebasan individu untuk mengungkapkan pendapat dan menentukan pilihannya, nilai-nilai, tanggung jawab personal, otonomi, tujuan dan pemaknaan. Seperti halnya media sosial Twitter yang merupakan hasil dari teknologi komunikasi, dimana dengan digitalisasi, Twitter dapat diakses melalui smartphone atau telepon pintar sehingga manusia dapat dengan mudah saling terhubung melalui internet dan membentuk lingkungannya sendiri dan juga membebaskan penggunanya untuk berpendapat dan menentukan pilihannya, salah satunya berinteraksi dengan idolanya, dan terhubung dengan sesama penggemar BTOB.

Kemudian teori yang dikaitkan dalam penelitian ini adalah teori fitrah. Kata fitrah yang di taraduf-kan (disamakan) dengan khalaqa menurut Achmadi, sebagaimana dikutip oleh Utsman Abu Bakar dan Surohim berarti kejadian asal. Bila dikaitkan dengan kejadian manusia, maka pengertiannya adalah kejadian asal atau pola dasar manusia, dan bila dikaitakan dengan 
sifat-sifat manusia maka pengertiannya ialah sifat asli kodrati yang ada pada manusia. Dengan adanya fitrah dalam diri manusia, maka diharapkan manusia dapat mengimplikasi dirinya dalam kehidupan dengan sadar diri akan tugas dan tanggung jawabnya sebagai manusia di bumi (khalifah fil ardi). Sama halnya dengan seorang penggemar, mereka membentuk sifat asli manusia secara alami melalui kebiasaan-kebiasaan mereka dari penggunaan media sosial Twitter, sehingga dari sanalah terbentuk sifat kodrati. Sifat kodrati mereka berupa kebiasaan positif seperti menyumbangkan donasi kepada yang membutuhkan melalui proyek-proyek positif yang diadakan oleh penggemar, dan mereka ikuti melalui media sosial twitter.

Teori selanjutnya adalah teori hirarki kebutuhan, bahwa dalam mencapai kepuasan kebutuhan, seseorang harus berjenjang, tidak perduli seberapa tinggi jenjang yang sudah dilewati, kalau jenjang dibawah mengalami ketidakpuasan atau tingkat kepuasannya masih sangat kecil, dia akan kembali ke jenjang yang tak terpuaskan itu sampai memperoleh tingkat kepuasan yang dikehendaki.

Teori terakhir yang dikaitkan dan digunakan untuk pengujian dalam penelitian ini ialah teori uses and gratification, yaitu media massa harus bersaing dengan sumber-sumber lain untuk memuaskan kebutuhannya. Kebutuhan yang dipenuhi media lebih luas. Bagaimana kebutuhan ini terpenuhi melalui konsumsi media amat bergantung kepada perilaku khalayak yang bersangkutan. Teori ini berkaitan juga dengan penggemar BTOB yang kebutuhannya informasinya terpenuhi melalui media sosial twitter, sehingga terbentuklah sikap fanatisme penggemar.

Setelah diteliti, bahwa penggemar BTOB di Kota Bandung mengungkapkan sikap fanatisme mereka melalui media sosial twitter, seperti mendapat bahan untuk berinteraksi dengan orang lain, mereka juga menggunakan twitter sebagai sarana untuk bersantai menghilangkan rasa bosan, untuk hiburan dan kesenangan. Kemudian penggemar BTOB di Kota Bandung sebagian besar menggunakan Twitter 5-6 kali per minggu. Melalui kebiasaan mereka menggunakan media sosial twitter, mereka mengungkapkan bahwa hal tersebut dapat menunjang hobi untuk bertukar informasi dengan sesama penggemar BTOB. Selanjutnya, dengan adanya media sosial Twitter, para penggemar BTOB di Kota Bandung merasa senang karena dapat mengekspresikan kegemaran terhadap boyband BTOB, mereka juga tidak segan-segan untuk mengungkapkan ketidaksukaan mereka bila ada seseorang yang memberikan komentar negatif mengenai boyband BTOB melalui media sosial Twitter, dan juga mereka akan bangga bila ada seseorang yang memberikan komentar positif mengenai boyband BTOB melalui media sosial Twitter.

Dengan demikian dapat disimpulkan dari hasil penelitian dan teori menunjukkan bahwa ternyata penggunaan media sosial twitter berpengaruh terhadap sikap fanatisme penggemar BTOB di Kota Bandung.

\section{Penutup}

a. Kesimpulan

Hasil analisis regresi berganda penelitian ini menunjukkan bahwa nilai konstanta adalah sebesar 8.846, hal ini dapat diartikan bahwa variabel Kebutuhan (Need), Frekuensi dan Durasi jika tidak ada perubahan maka Sikap Fanatisme Penggemar cenderung nerpengaruh positif. Nilai koefisien Kebutuhan (Need) sebesar 0.440 bernilai positif, hal ini dapat diartikan bahwa kebutuhan (Need) berpengaruh terhadap sikap fanatisme penggemar. Nilai koefisien Frekuensi $(\beta 1)$ sebesar 0.114 dengan nilai negatif, hal ini berarti bahwa Frekuensi (X1) tidak berpengaruh terhadap sikap fanatisme penggemar. Dan nilai koefisien Durasi ( $\beta 2)$ sebesar 0.307 dengan nilai positif, hal ini berarti bahwa Durasi (X2) 
berpengaruh terhadap sikap fanatisme penggemar.

Berdasarkan hasil uji t diketahui bahwa t-hitung dari konstanta adalah 2.731 lebih besar dari t-tabel 1.985 dan diperoleh nilai signifikansi 0.008 lebih kecil dari taraf signifikansi 0.05 . Oleh karena itu dapat disimpulkan bahwa terdapat pengaruh antara penggunaan media sosial twitter terhadap fanatisme penggemar.

Berdasarkan analisis koefisien determinasi dengan menggunakan program SPSS menunjukkan bahwa koefisien determinasi (adjusted $\mathrm{R}^{2}$ ) yang diperoleh sebesar 0.361. Hal ini dapat diartikan bahwa $36.1 \%$ sikap fanatisme penggemar (Y) dapat dipengaruhi oleh variabel kebutuhan, frekuensi (X1) dan durasi (X2). Sedangkan sisanya yaitu $63.9 \%(100 \%$ - 36.1\%) dipengaruhi oleh variabel-variabel lainnya yang tidak diteliti dalam penelitian ini.

\section{DAFTAR PUSTAKA}

Abin, Syamsuddin Makmun. 2003. Psikologi Pendidikan. Bandung: PT Rosda

Karya Remaja.

Abraham H. Maslow. 1994. Motivasi dan Kepribadian (Teori Motivasi dengan Pendekatan Hierarki Kebutuhan Manusia). PT PBP, Jakarta

Albert, Kurniawan. 2009. Belajar mudah SPSS untuk pemula. Yogyakarta:

Mediakom

Ardianto, Elvinaro. 2011. Metodelogi

Penelitian untuk Public Relations

Kuantitatif dan Kualitatif.

Bandung: Simbiosa Rekatama Media

Ardianto, Elvinaro \& Bambang QAness. 2007. Filsafat Ilmu Komunikasi.

Bandung: Simbiosa Rekatama

Media

Arikunto, Suharsimi. 1986. Prosedur

Penelitian Suatu Pendekatan Praktek, Jakarta: Bina Aksara.

Aulia, Muhammad. 2010. Belajar Teknologi dengan Mudah. Depok: Gramedia

Pustaka.

\section{b. Saran}

Disarankan untuk penggemar agar dapat menggunakan media sosial twitter lebih bijak lagi, terlebih dalam pengungkapan sikap fanatisme. Agar tidak memicu masalah-masalah yang kemungkinan dapat terjadi kepada sesama penggemar dengan menggunakan media sosial twitter yang berlebihan.

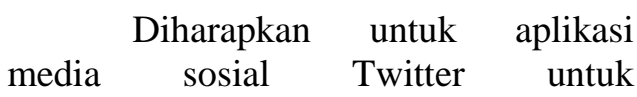
mengembangkan aplikasinya dengan fitur-fitur yang lebih menarik dan dapat menunjang kebutuhan penggunanya termasuk penggemar idola Korea untuk berkomunikasi dengan sesama penggemar melalui aplikasi media sosial Twitter.

Disarankan untuk peneliti lain agar dapat meneliti variabel lain yang dapat memengaruhi Pengungkapan diri Mahasiswa yang tidak diteliti dalam penelitian ini.

Atipinastika, Ayu. 2012. Korean Wave: Semua Serba Korea, Yogyakarta: Araska

Azwar, Saifuddin. 2016. Sikap Manusia, Teori dan Pengukurannya. Yogyakarta: Pustaka Pelajar

Bambang, Prasetyo. Lina, Miftahul. 2005. Metode Penelitian Kuantitatif. Jakarta:

\section{PT Raja Grafindo}

Boyd, Danah M. dan Ellison, Nicole B. 2008. Social Network Sites: Definition, History, and Scholarship. Journal of Computer-Mediated Communication.

Buente, Wayne dan Alice Robbin. 2008. Trends in Internet Information Behavior: 2000-2004".

Bungin, Burhan. 2006. Sosiologi Komunikasi: Teori, Paradigm, dan Diskursus

Teknologi Komunikasi di Masyarakat. Jakarta: Kencana Prenada Media Group

Djalaluddin, Rakhmat. 2005. Metode Penelitian Komunikasi. Bandung: PT Remaja Rosdakarya. 
Effendy, Onong Uchjana. 2003. Ilmu, Teori dan Filsafat Komunikasi. Bandung:

$$
\text { PT. Citra Aditya Bakti }
$$

Elcom. 2009. Twitter: Best Social Networking. Yogyakarta: Penerbit Andi. Fisher, Aubrey. 1978. Perspectives on Human Communication. Bandung: CV Remadja Karya

Hadi, Mulya. 2009. Twitter untuk Orang Awam. Palembang: Maxikom.

Hasbiansyah, O. 2004. Konstelasi Paradigma Objektif dan Subjektif dalam Penelitian Komunikasi dan Sosial. Mediator, Vol. 5.

Herdianto, Yayan. Pengaruh Situs Jejaring Sosial Facebook Terhadap Pola Hurlock. E. B. Psikologi Perkembangan: Suatu Pendekatan Sepanjang Rentan

Horrigan, John B. 2002. New Internet Users: What They do Online, What They

Don't and Implications for the Net's future. Journal Pew Internet and American Life Project. Melalui http://www.pewinternet.org.

Kurnia, Novi. 2005. Perkembangan Teknologi Komunikasi dan Media Baru: Implikasi terhadap Teori

Komunikasi. Jakarta: MediaTor.

Kurniawan, Dwi. 2016. "Fitrah dan Implikasinya dalam Teori Pengembangan Manusia menurut Al-Qur'an dan Al-Hadist"

Latief, Khatib. A. 2015. Analisis Koefisien Korelasi Rank Spearman. Jakarta.

Littlejohn, Stephen W. 2016. Ensiklopedia Teori Komunikasi. Jakarta: Kencana.

Madcoms. 2010. Facebook, Twitter dan Plurk dalam Satu Genggaman. Yogyakarta: Penerbit Andi.

Milstei, Sarah and Tim O'Reilly. 2009. The Twitter Book. USA: O'Reilly Media Inc.

Morissan. 2013. Teori Komunikasi: Individu Hingga Massa. Jakarta: Prenadamedia Group
Mozee, Sam. 2012. The Impact of Social Media use on Academic Performance at one Urban University: A Pilot Study. Mississippi Urban Research Center. Journal of Rural and Urban Research

Mujahid. 2005. Konsep Fitrah dalam Islam dan Implikasinya terhadap Pendidikan Islam Vol.2.

Nasrullah, Rulli. 2015. Media Sosial: Perspektif Komunikasi, Budaya, dan Sosioteknologi. Bandung:

Simbiosa Rekatama Media

Nurhadi, Zikri Fachrul. 2017. Teori Komunikasi Kontemporer. Jakarta: Persada

Media Group

Nastiti, Aulia. D. 2010. "Korean Wave" di Indonesia: Antara Budaya Pop, Internet, dan Fanatisme Pada Remaja (Studi Kasus Terhadap Situs Assian Fans Club Di Indonesia Dalam Perspektif Komunikasi Antar Budaya). Journal of Communication.

Pertiwi, Sella Ayu. 2013. Konformitas dan Fanatisme Pada Remaja Korean Wave

(Penelitian pada Komunitas Super Junior Fans Club ELF "Ever Lasting Friend") di Samarinda. Samarinda: ejournal.psikologi.fisipunmul.org

Rakhmat, Jalaluddin. 2015. Psikologi Komunikasi. Bandung: PT. Remaja Rosdakarya 2014. Metode

Penelitian Komunikasi. Bandung: PT. Remaja Rosdakarya

Room, V. 1964. Psikologi Sosial. Terjemahan : Michael Adryanto. Jakarta

Erlangga

Sarlito, Wirawan Sarwono. 2006. Teoriteori Psikologi Sosial. Jakarta: Raja Grafindo Persada

Sarwono, S Wirawan. 2000. Psikologi Remaja. Jakarta: Raja Grafindo Persada Seregina, A., Koivisto, E., dan Mattila, P. 2011. Fanaticism-Its Developmentand 
Meanings in Consumers Lives. Journal of Aalto University School of Economics.

Sri Rumini \& Siti Sundari. 2004.

Perkembangan Anak \& Remaja. Jakarta:

Rineka

Cipta.

Sugiyono. 2016. Metode Penelitian

Kombinasi (Mixed Methods). Bandung: Alfabeta

Suryabrata, Sumadi. 2015. Psikologi

Kepribadian. Jakarta: PT Raja Grafindo Persada

Triandis, H. C. 1971. Attitude and Attitude Change. Canada: John Wiley \& Sons, inc.

Triton P.B. 2006. Terapan Riset Statistik Parametrik. Yogyakarta: Andi Offset.

Ulfianti, S. 2012. Fanatisme Remaja Indonesia Pada Korean Wave. Jurnal Artikel

Korean Wave.

Umar, Husein. 2000. Metodologi Penelitian. Jakarta: Gramedia Pustaka Umum

West, Richard. 2013. Pengantar Teori Komunikasi: Analisis dan Aplikasi. Jakarta:

Salemba Humanika
Wijayanti, Ardiani. A. 2012. Hallyu: Youngstres Fanaticism of Korean Pop Culture (Study of Hallyu Fans Yogyakarta City). Journal of Sociology.

\section{Sumber lain:}

Hasil wawancara dengan Penggemar dan Founder@BTOBIndonesia http://digilib.unila.ac.id/268/10/BAB\%2 520II.pdf https://id.m.wikipedia.org/wiki/Pengge mar https://id.wikipedia.org/wiki/Twitter https://id.wikipedia.org/wiki/Fanatisme http://en.wikipedia.org/wiki/Humanistic _psychology

http://www.ebookbrowse.com/metodolo gi-penelitian-kausal-komparatif-pdfd340159528

http://www.psikoterapis.com/?en_apaitu-fanatisme-\%2C72

http://www.penalaran-

unm.org/index.php/artikel-

nalar/penelitian/159-penelitian-

kausalkomparatif.html

Materi+07+-+TeoriAbrahamMaslow.pdf Undang-undang Republik Indonesia Nomor 11 Tahun 2008 tentang Informasi dan Transaksi Elektronik 